\title{
COMBINING STRATEGIC, OPERATIONAL AND FINANCIAL PERFORMANCE IN THE VIRTUAL ORGANISATION
}

\author{
David Walters \\ Professor of Management \\ Sydney Graduate School of Management \\ AUSTRALIA \\ d.walters@uws.edu.au
}

\begin{abstract}
The virtual business model is now commonplace across a range of industries and international boundaries. The attraction of the 'virtual' concept is well documented and numerous examples of its efficacy exist in the literature. Applications of the concept vary from the complete application of the virtual model to partial solutions to meet a need for specialist process and capability requirements. This paper identifies some of the issues that will have an impact on planning performance systems. Clearly the notion of 'asset leverage' and' zero working capital' are corporate ideals but before these can be anywhere near realities some problems must first be resolved. This paper addresses
\end{abstract}

\section{INTRODUCTION}

The growth of virtual business models has outpaced the ability to plan and to measure their performance. This paper reviews the growth of "new economy" business models and then explores the contributions of the planning, control and performance literature within the context of these new structures.

The paper will consider the implications for the virtual business organisation of integrating and coordinating the operating and cash cycles of component firms from not only an operational perspective but from the strategic directions and purposes of each constituent. While there is an inherent logic in the emerging virtual structure there appears not to be an accompanying "planning, performance and control" model with which to evaluate the efficacy of the alternatives. In recent months the major consultancy companies have been publishing articles that have paralleled the strategic issues for virtual business structures and performance management. What is now required is an attempt at combining both. This paper will identify recent contributions to both topics and demonstrate how they can be merged into a viable model.

\section{STRATEGY, ORGANISATION AND THE 'PLANNING ENVIRONMENT'}

Roberts (2004) suggests that achieving high performance in a business results from 
establishing and maintaining a fit among three elements; the firm's strategy, its organisational design and its environment. Roberts cites the seminal work of Chandler (1962) in which Chandler presented an argument that "structure follows strategy" and that organisation is the mechanism through which strategy is realised.

Over forty years have passed and while Chandler's proposition still holds there are a number of changes that have occurred to 'planning environment' with which the $21^{\text {st }}$ century organisation now has to consider. The combined impact of knowledge, technology, process and relationship management are beginning to create a new environment, one in which an organisation is confronted with first identifying the strategic critical industry success drivers and then designing a business model that will offer a position that offers exclusive competitiveness - one of sustainable competitive advantage. There is evidence to suggest that these four generic frameworks appear to be becoming important features in planning in "new economy" business models. Disparate but linked threads are evident in the literature

These macro critical success frameworks should be used to help obtain a profile of industry characteristics against which it is then possible to measure 'organisational' performance and consider the influence of the drivers. Having identified the "critical success drivers" the next task is to identify where they are located - who owns them and how they can be accessed. A major skill in the management of a virtual enterprise is to establish the most effective position for a partner within the virtual community. Clearly no partner will agree to become involved unless the outcome will be to their benefit - that is they must be convinced that they will become "better off".

\subsection{From Vertical to Virtual Structures}

Problems with making shareholder value management effective coincided with the increasing appeal of virtual, or holistic, structures. The importance of achieving customer satisfaction in order to achieve shareholder satisfaction became very obvious and 'enlightened' management realised that the two should be seen as convergent rather than parallel and certainly not divergent. The virtual organisation offers an opportunity to identify the relationships that exist between customer satisfaction processes, capabilities and assets. With these linkages identified it is then easier to match the organisation's resources to a set of objectives that optimise customer and shareholder expectations. However two steps remain - that of identifying partners whose expertise and asset bases can make the "organisation" effective, more effective than that of competitors, and convincing the 'partners' to become involved in what has become known as the virtual business model

Roberts op cit suggests that essential to organisational interdependencies are two key tasks coordination and motivation and these becomes the role of the "vertical architect" or "virtual organiser". This role is larger than Roberts suggests. It combines vision and the ability to be able to integrate the relevant skills and resources (processes, capabilities and assets) to meet opportunities and the associated customer (and the broader base of stakeholders) expectations with a business model in which some exclusivity will offer a measure of competitive advantage. Two options emerge, product innovation or process innovation. Typically the virtual organisation is process innovation led. Strategically effective organisation structures are put in place that creates operationally efficient value delivery systems. Roberts identifies a number of such as Dell, Nike, Benetton, and 
the personal computer industry. Having found an acceptable structure successful integration is the dependent upon coordination and motivation

\section{PERFORMANCE MEASUREMENT IN VIRTUAL ORGANISATIONS IS QUALITATIVE AND QUANTITATIVE AND DIFFICULT}

\subsection{Performance Planning and Management}

Clearly it is more difficult to implement strategies in which a number of participants benefit but the growth of such structures is evidence of the fact that they can and are successful. Normann's (2001) argument concerning the management rather than the ownership of assets is fundamental to the virtual business. The attraction to all partners is the release from the burden of owning fixed assets and therefore being required to make decisions that are often volume oriented (a production orientation) rather than market based (customer centric). There is a strong incentive to reduce the burden of fixed costs and improve corporate performance through partnerships and alliances. The Australian Wine Industry this has proved to be a popular model, albeit one with problems.

The basic objective of any virtual organisation structure then is to provide value for both its customers and stakeholder partners. Given that both have clear views on what this comprises the structure should reflect the decision options available that can optimise this outcome. Figure 1 models this process. The model identifies revenues as being a response to the relevance of the organisations' value proposition. This response will be based upon the added value content and 'worth' to the target customer(s). But as figure 1 suggests there are both operational and strategic decision options and these involve marketing strategy responses that in turn are influenced by the added value expectations of customers and partners. Clearly time perspectives are important and the model reflects these. The model also reflects the overall need to establish strong competitive advantage and this is measured by considering the impact of the potential (and feasible) operational and strategic decision options.

\subsection{Managing for Strategic Cash Flow Effectiveness}

It is suggested that the primary measure of corporate success should be free cash flow rather than notions of "profit" that are by definition artificial constructs. In this sense cash flow is defined more from a managerial perspective and differs from the accounting definition that has taxation and financial reporting requirements. Within the context and structure of a virtual organization the components of free cash flow should follow the decision-making processes. Figure two identifies four decision points; revenue generation, the operational decisions that are concerned with inventory levels, and receivables and payables. Changes to operations strategies result in changes to cash requirements for working capital and fixed assets, thereby changing the asset base and the cash flow from assets. Strategic decisions concerning the investment in tangible assets (processes, capabilities and assets) and intangible assets (such as R\&D, brands, management and employee development) 
will impact on long-term cash flows. Free cash flow is influenced by funding structure decisions while value capture reflects the ability of the value organization to participate successfully and for each participant to meet its financial and marketing objectives.

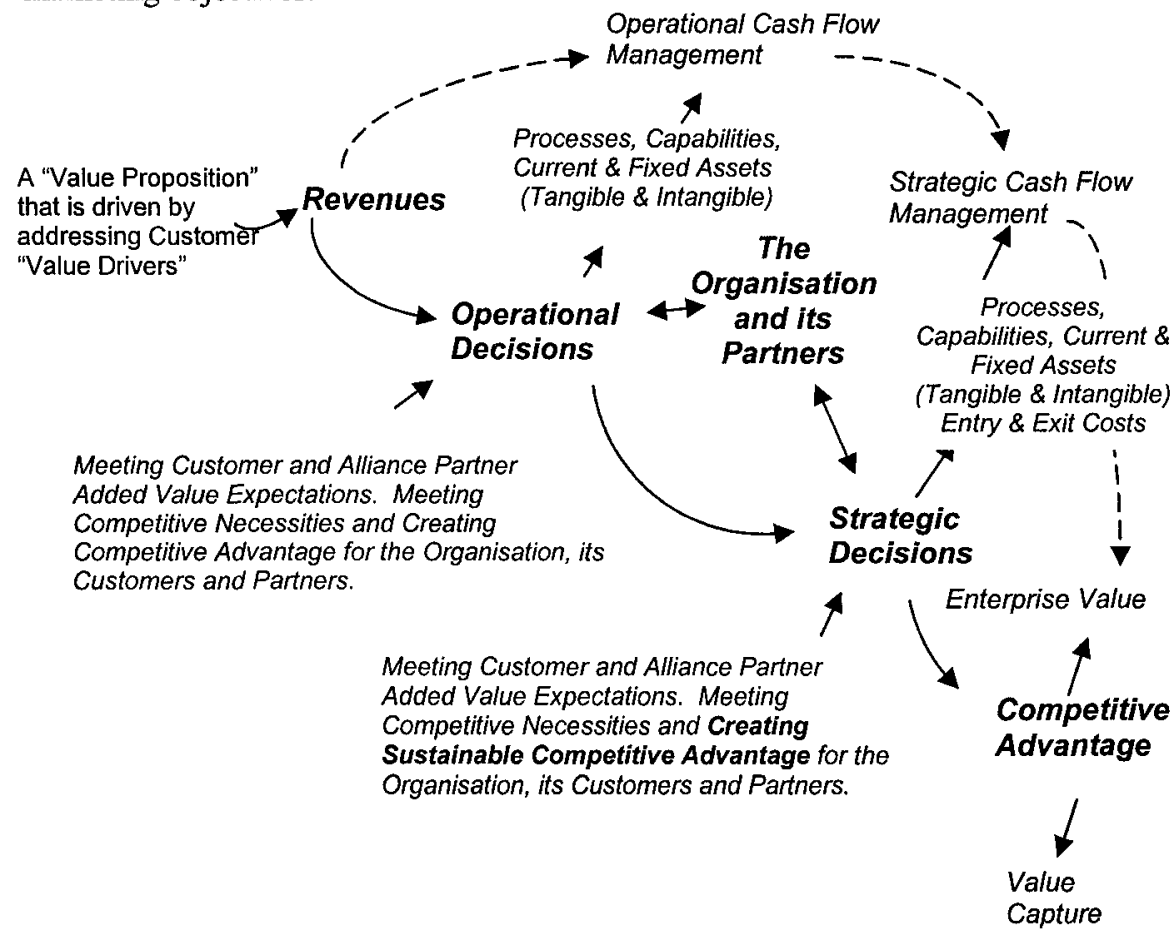

Figure 1: Successful Business Models Create Added Value for all Participants

Figure 2 reflects the structure and components of a virtual organisation cash flow model the model offers management an opportunity to evaluate alternative structures. For example operating cash flow profiles can be changed by modifying operations activities, a greater use of components and modules and focusing on assembly rather than component manufacturing can result in lower levels of inventories and decreased cash cycles. The introduction of JIT systems also change inventory and payables profiles. Supplier rationalisation can result in improved operating profit and credit terms. Decisions to outsource all or some of the manufacturing process will have similar effects.

In the long-term changes in strategic direction are likely to have implications for cash flow management. For example a decision to pursue an opportunity in an adjacent market segment can have significant implications for both working capital and fixed assets. A specialist cheese manufacturer found this at considerable cost. The mature cheddar segment appeared to have attractions. Competition was relatively low, and the market for specialist cheeses was being expanded by large multiple retailers. The costs of entry were an increase in both storage costs and inventory - the mature cheese market involved a maturing process period of nine months - a period of time in which the added value could not be realised and one in which the product required storage space. Large volume customers who used their 
size to protract accounts payment exacerbated the cash flow problems. Adjusting cash flow from assets and strategic cash flow profiles can have significant impact on free cash flow. As figure two suggests free cash flow is influenced by, not only the amount or size of the funding requirements, but also by the type of funds. Debt funding incurs interest charges (an increase in operating cash flow) while equity funding attracts fund raising costs and may dilute managerial control of the business. Clearly the virtual organisation concept is attractive as it offers a means by which financial performance can be planed and managed.

Revenues Less Discounts less Wages and Salaries less Materials, components and services Less Capital servicing and maintenance costs less Overhead expenses = Operating Cash flow

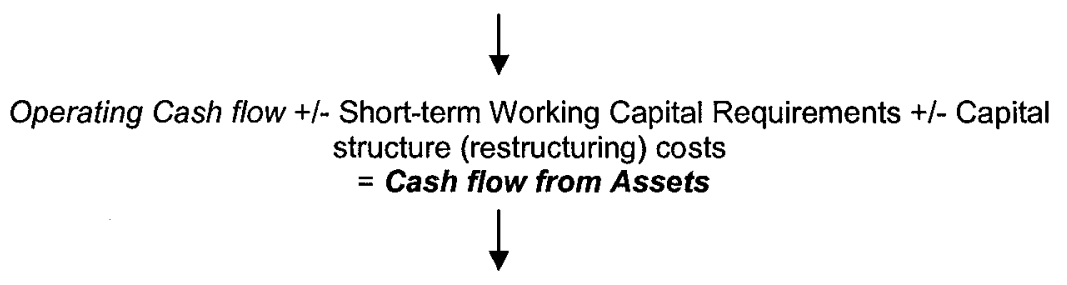

Cash flow from Assets +/- Fixed Assets (Tangible \& Intangible) +/- Long-term

Working Capital Requirements+/- "Entry and Exit" Costs

=Strategic Cash flow

Strategic Cash flow +1 - Changes in Equity \& Debt funding = Free cash flow

Figure 2: The determinants of free cash flow: the primary business objective

\subsection{Managing Working Capital and Fixed Assets}

Within the virtual organisation the deployment of both working capital and fixed assets is important. There are the cash flow implications that have been identified in the preceding paragraphs but there also issues concerning customer service. A significant aspect of customer value perceptions concerns service delivery and this has two characteristics. One is the traditional role of inventory in the supply chain but the other has implications for "value in use" and the customer's view of life cycle costs. Often the purchase decision is influenced by service packages (including installation, maintenance, staff training, etc) that can reduce the total costs of purchasing and operations.

Figure 3 explores these short and long-term decisions. Given a clearly defined demand chain profile results in specific value drivers that can be explored, not only in their ability to deliver added value to customers, but also for cost-efficient delivery alternatives. It follows that alternative formats for working capital, fixed assets and the implications for funding can be evaluated. However before a final decision can be made the impact on the operational gearing of the virtual business must be considered. If the resulting structure is one with a high fixed cost element there is inherent risk to the "organization" together with a lack of flexibility. Not 
could this result in excess capacity but it is likely to influence investors' funding decisions. This in turn can have implications for borrowing rates and the 'returns spread' of the organisation. Typically this is influenced by the relationship between debt and equity funding, however if investors (i.e. the banks) were to be concerned at the organisation's ability to respond to market fluctuations then the level of operational gearing could also influence their decision. Clearly one of the major benefits of the virtual organization is the ability to choose a structure that optimises return and risk.
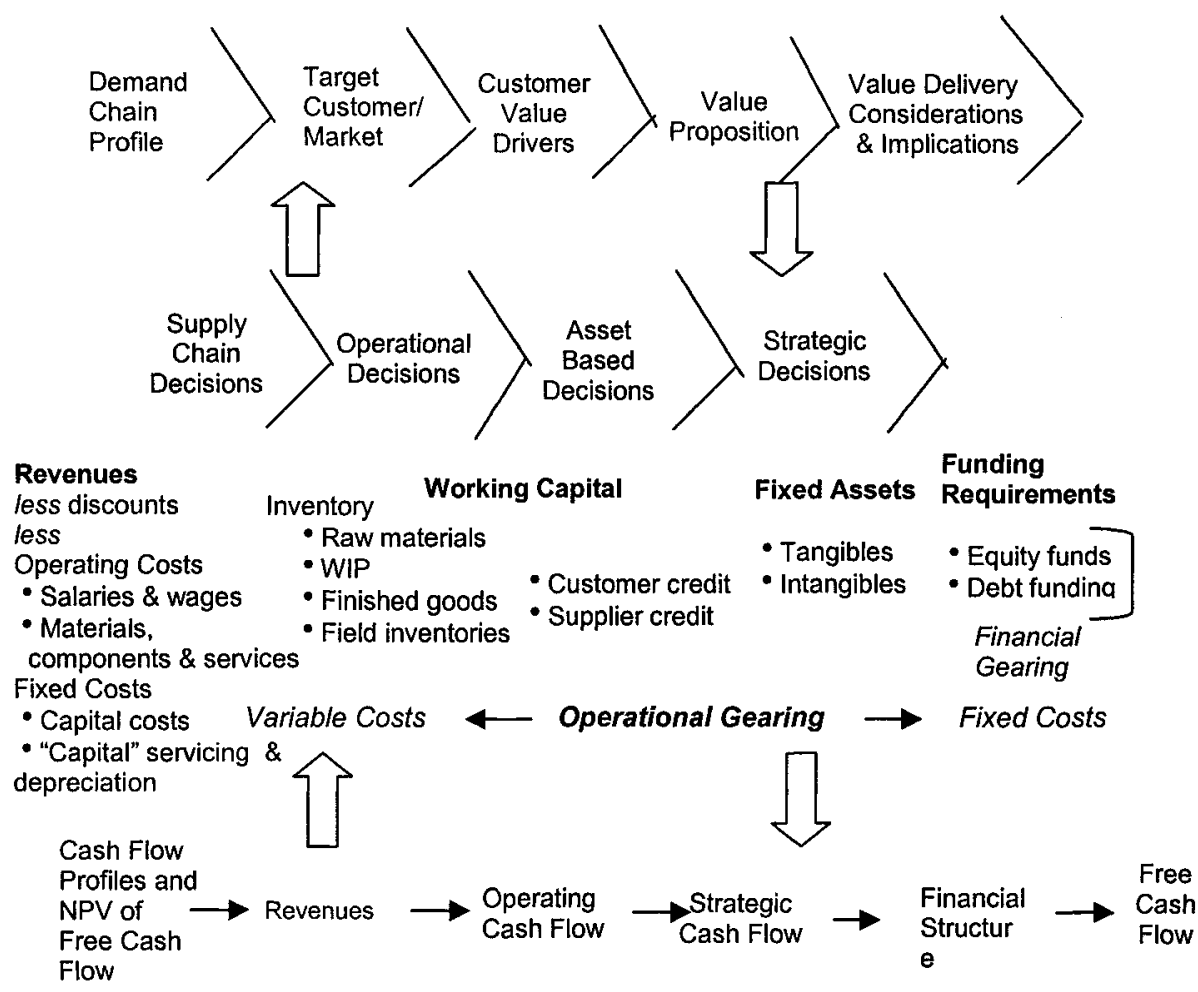

Figure 3: Managing Working Capital and Fixed Assets in the Virtual Business

\section{AN EXAMPLE}

Developments in the Australian wine industry are typical of a model based upon a virtual model with little or no fixed investment and the minimisation of working capital. The objective is to achieve a low investment to sales ratio. This takes into account assumptions concerning inventory levels that service target markets, realistic receivables and payables and a targeted pricing policy that generates target gross margins. The compelling philosophical attractiveness of the model can be demonstrated by the following two simple examples that compare a virtual wine business with a typical traditional wine business (which grows, makes and stores around $70 \%$ of its sales volumes). 
In a low capital intensity (virtual winery) model the investment/sales ratio is typically lower than that of traditional models by a significant amount - 30 percent compared with as much as 120 percent. Assuming similar costs and product quality the required EBIT/Funds Employed ratio becomes a much lower figure. For example with a Capital Intensity Ratio of say 40/50 percent compared to the traditional level of between 100 to 200 percent the required EBIT/Funds Employed figure can be as low as 10 percent, considerably less than the 30 percent required for viability by the traditional model. It follows that target revenues are also lower, often by some 30 percent - in retail terms this may be as much as 25 percent less per bottle for the same quality wine! As a result the EBIT/Funds Employed ratio can show an impressive 75 percent for the 'virtual' model versus approximately five percent for the traditional winery model.

Cash flow improvements are equally significant. It can be calculated that, based on the assumptions of same revenues, EBIT/Funds Employed and debt, the cash generated can be shown to improve by a factor of between three and four times.

Clearly, the low capital intensity model begs the question as to whether a secure long term supply of input product and supplementary services are available from third parties. In the context of the Australian wine industry historically, a significant proportion of the wine industry's production volume has been traded between industry members as bulk "commodity product" and specialist bulk businesses have been established whose sole purpose is to supply bulk inputs (to other businesses). Huge volumes enabled these businesses to supply input product at very attractive prices on flexible payment terms. Rosemount is an example. Until the early 1990's Rosemount was a traditional wine business. It effectively adopted the low capital intensity model in the mid 1990's in order to fund its growth. This was achieved during a period of relative under supply and rising grape prices. The strategy is particularly attractive if it is perceived that over supply and falling prices have at least 3-4 years yet to run.

Under such circumstances a virtual winery would adjust the proportion of requirements supplied between "spot" purchases (under short-term contracts), and longer-term contracts. Supplementary services are typically available from third party sources for operational tasks such as facilities where it can "fine tune" and store "product" prior to final processing and contract storage of finished goods.

\section{CONCLUDING REMARKS}

This paper has set out some of the performance planning and control topics requiring resolution if the virtual business model concept is to become more widely accepted. It recognizes that the concept is not simply a co-operative response to market demands, but has its own tensions and conflicts. This need to be both identified and included in a firms strategic positioning and the construction of its business model. 


\section{REFERENCES}

Blumentritt R and R Johnston (1999) "Towards a strategy for knowledge management," Technology Analysis and Strategic Management, September, Abingdon

Chandler A (1962) Strategy and Structure, Cambridge, MIT Press, MA

Hagel, J and M Singer (1999) "Unbundling the corporation", Harvard Business Review, 77(2).

Hacki R and J Lighton (2005) "The future of the networked company", McKinsey Quarterly, 11 February

Irani $\mathrm{Z}$ and $\mathrm{P}$ Love (2001) "The Propogation of Technology Management Taxonomies for Evaluating Investments in Information Systems" Journal of Management Information Systems, Winter 2000-2001

Jarillo J C (1993) Strategic Networks-Creating the Borderless Organisation, Butterworth-Heinemann, Oxford

'Normann R, (2001) Reframing Business, Wiley, Chichester

Roberts D J (2004) The Modern Firm - Organisational Design for Performance and Growth, OUP, Oxford

Zineldin M (1997) Strategic Relationship Management A Multi-Dimensional Perspective: Towards a New Co-opetive Framework on Managing, Marketing and Organizing, Almqvist \& Wiksell International AB, Stockholm 